\title{
Psychological Aspects of Transitive Verbs ${ }^{1}$
}

\author{
Donald J. Polzella \\ University of Michigan, Ann Arbor, Michigan 48104 \\ AND \\ Nicholas L. ROHRMAN \\ Florida State University, Tallahassee, Florida 32306
}

\begin{abstract}
It has previously been shown that transitive verbs are more difficult to recall than intransitive. Experiment I replicated this finding. Experiment II examined the associations to, and response latencies of, transitive and intransitive verbs. Latencies of responses did not differ, but the form class of responses was significantly different. Transitive verbs elicited more noun responses. It is suggested that the lexical entry provided for transitive verbs by Chomsky is psychologically real and will account for the observed differences.
\end{abstract}

Recent studies, Rohrman (1968), Rohrman and Polzella (1968) concerned with the role of deep syntactic structure in the recall of nominalizations can be interpreted as suggesting that transitive verbs are more difficult to recall than intransitive. These nominalizations (e.g., growling lions, digging holes) are equivalent in surface structure but differ in deep structure complexity. However, in the first item the verb is intransitive while in the second it is transitive. Thus, it may be that transitive verbs are more difficult to recall whether they are nominalized or not. In fact, another recent study (Rohrman, 1970) has shown just this. Transitive verbs in the gerundive form, verb + ing, such as digging, in isolation are more difficult to recall than intransitives, such as growling. However, in this study several items were ambiguous $(6.25 \%)$, such as flying, and could not be clearly labeled as transitive or intransitive, and these data are not absolutely

\footnotetext{
${ }^{1}$ This paper is based on a Master's thesis conducted by the first author under the direction of the second and submitted to the faculty of Bucknell University. Results were presented at the meeting of the Eastern Psychological Association, Philadelphia, April, 1969. This research was supported by NSF Grant GB 7614 to the second author.
}

conclusive. Thus, a replication without the small number of ambiguities would be most useful. Additionally, since Rohrman's items were gerunds, it would be informative to determine if the recall difference is found with verbs in other forms.

The present study is an attempt to determine the characteristics of transitive and intransitive verbs-first, by determining if the recall difference is real; and second, if it is, to determine the reasons for this difference.

\section{EXPERIMENT I}

\section{Method}

Subjects. Thirty undergraduates enrolled in introductory psychology courses at Bucknell University fulfilling a course requirement served as $S$ s.

Materials and procedures. The $S \mathrm{~s}$ were presented with two lists of 14 verbs, half transitive and half intransitive. Verbs were in the infinitive form, verb, with no markers, such as accuse and vacillate; and the transitives were of the class that does not undergo object deletion. Items were closely matched for length and frequency. Items were presented tachistoscopically one at a time with an exposure rate of $4 \mathrm{sec}$. and an interitem interval of $2 \mathrm{sec}$. Each $S$ received a different randomization of the two lists. Half the $S \mathrm{~s}$ viewed List 1 first and half viewed List 2 first. The $S s$ were instructed for immediate written free recall. 


\section{Results}

More intransitives were recalled than transitives. A mean of 3.6 transitives were recalled on each list as compared to a mean of 4.1 intransitives. A two-factor repeated-measures analysis of variance showed the difference to be significant, $F(1,11)=5.89, p<.05$. No other effects were significant.

\section{Discussion}

It appears that the recall difference between transitive and intransitive verbs is real and it occurs with the verbs in several forms. Since items were very closely matched for length and frequency, we cannot appeal to explanations involving obvious observable differences between the items, and the results of Experiment I must be discussed in terms of qualitative differences between transitive and intransitive verbs.

By definition, intransitive verbs are those which do not take an object, while transitive verbs normally do. For example, the intransitive verb exist may be used in the sentence John exists. By adding an object the sentence becomes meaningless, for example John exists something. On the other hand the transitive verb avoid may be used in the sentence John avoids something. Without the object something, however, the sentence is incomplete, for example, John avoids. (We exclude from present consideration the subset of transitives which undergo object deletion.) It is, perhaps, then reasonable to assume that transitive verbs in isolation are less meaningful than intransitive verbs, because the transitives are incomplete cognitive units. Thus, a measure of meaningfulness might show differences between these items.

We, therefore, collected $m$ data from $51 S s$, following Noble's (1952) procedure, for the items of Experiment I. Intransitives elicited a mean of 8.09 associations and transitives a mean of 7.95. A $t$ test showed the difference to be insignificant, $t(50)=1.27$, $p>.10$. Thus, these items do not differ in meaningfulness.
However, the necessity for providing an object for transitives may have other implications. It seems obvious that native speakers are aware of the distinction between transitive and intransitive verbs. And perhaps $S$ s are implicitly providing an object for the transitive verbs thus completing the incomplete unit and making a larger unit to store in memory. This does not occur with intransitives and hence they are easier to recall. What we are suggesting is that transitive verbs have a close relationship with nouns that does not exist between intransitives and nouns. Chomsky (1965) suggested something very much like this in the marking of the syntactic features of these items. The lexical entry for transitive verbs is, $[+\mathrm{V},+\ldots \mathrm{NP}]$, and the intransitive is $[+\mathrm{V},+-]$. This makes explicit the relationship we have been discussing. Notice that for the transitive verbs the environment is specified to include a noun phrase and that this specification is absent for the intransitive.

The supposition that $S$ s implicitly associate an object to transitive verbs has a number of testable implications. First of all, if nouns are so intimately associated with transitive verbs they should be dominant in $S s^{\prime}$ verbal repertoires, and we should expect more nouns as responses to transitive verbs in an association task. Second, we should expect the response latency to be less for transitive verbs, because the verbal repertoire is highly focused, whereas for intransitives the verbal repertoire is relatively diffuse. The reduced response latency should be especially marked in the case of noun responses. These hypotheses were tested in Experiment II.

\section{EXPERIMENT II}

\section{Method}

Subjects. Thirty-four undergraduates enrolled in introductory psychology classes at Bucknell University served in the experiment.

Procedure. Each $S$ was presented orally with the 14 transitive and 14 intransitive verbs used in Experiment I. Each $S$ received a different randomization of the 28 
items. Presentation by the experimenter activated a voice operated relay which started a reaction timer and the response of the $S$ stopped the timer. The $S$ s were instructed to say the first word that came to mind. To familiarize the $S$ s with the task and apparatus and to establish a stable rate of responding, prior to the association task proper, $S$ s were instructed to give discrete associations to a list of 30 syntactically nonambiguous nouns. The $S$ s were then presented with the verbs for association without further instruction.

\section{Results}

A mean of 7.6 noun responses were elicited by the transitive verbs as compared to a mean of 4.1 elicited by the intransitives. A $t$ test showed the difference to be highly significant, $t(33)=8.83, p<.002$. Table 1 shows the total number of responses categorized by grammatical class. As can be seen many more nouns are elicited by transitives. For transitive verbs a sizable majority of the associations provided, $55 \%$, are nouns while only $41 \%$ are verbs. For intransitive verbs the relationship reverses, $56 \%$ verb responses and $29 \%$ noun responses.

TABLE 1

Number of Responses Elicited by Transittve and Intransitive Verbs by Grammatical Class

\begin{tabular}{lrrr}
\hline \multicolumn{1}{c}{ Response } & Transitive & Intransitive & Total \\
\hline Noun & 259 & 141 & 400 \\
Verb & 197 & 261 & 458 \\
Adjective & 11 & 38 & 49 \\
Adverb & 3 & 15 & 18 \\
Other & 3 & 18 & 21 \\
Total & 473 & 473 & 946 \\
\hline
\end{tabular}

Mean response latencies are summarized in Table 2. Because of the extremely small number of responses in the adjective, adverb and other classes, latency data were analyzed only for the noun and verb classes. Analysis of variance showed no significant difference in overall response latency, although the difference is in the predicted direction. However, there was a highly significant interaction between stimulus verb type and the form class of the response, $F(1,29)=8.69, p<.01$. A Newman-Keuls test of ordered means yielded three significant comparisons: Within the noun-response class, responses to transitive verbs are faster than responses to intransitives; verb responses to intransitives are faster than noun responses to intransitives; verb responses to transitives are faster than noun responses to intransitives $(p<.05$ in all cases). Of these three only the first is of great interest. Given, then, that the response is a noun it is faster to a transitive verb than to an intransitive.

\section{TABLE 2}

Mean Response Latencies in Seconds

\begin{tabular}{lcc}
\hline \multicolumn{1}{c}{ Response } & Transitive & Intransitive \\
\hline Noun & 2.09 & 2.52 \\
Verb & 2.29 & 2.18 \\
Overall mean & 2.19 & 2.35 \\
\hline
\end{tabular}

\section{Discussion}

The fact that noun responses are faster to transitive verbs than intransitives seems to add at least partial support to our second prediction. This coupled with the generally predictable difference in form class of associate allows us to feel some confidence in our hypothesis about the close relationship between transitive verbs and nouns and $S s^{\prime}$ implicit responses to the transitive verbs.

These results have a number of important implications. One of the current disputes in linguistic theory is between the "lexicalist" and "transformationalist" positions. These terms are from Chomsky's (in press) paper, "Remarks on Nominalization." Very briefly, the dispute concerns the representation of information such as selection restrictions, transitive and intransitive, and a great many other things. Oversimplifying somewhat, Chomsky argued that a great deal of information is represented in the lexical component of the base structure and this leads to a simplification of the transformational component. 
The alternative view complicates the phrase structure and transformational components while simplifying the lexicon. The issue at present is far from settled.

Our data, which show recall differences in single words, indicate that the feature representation given by Chomsky does have some psychological validity. The more complex representation required by transitive verbs, as shown above, has a corresponding psychological complexity; these verbs are more difficult to recall. Thus, our data lend some support to the lexicalist position. Wall, Simison, and Stewart (1968) have shown that transitive verbs are more difficult to recall than causative verbs and we feel our data are consistent with theirs. Thus, the available psychological evidence favors Chomsky's view.

These data also bear on the notion of syntagmatic and paradigmatic associations. It has commonly been supposed that adult word associations are predominantly paradigmatic. Our data showing a large number of noun responses to verb stimuli make this somewhat questionable. However, since we preceded our association task with noun practice items this consideration should probably be interpreted cautiously. We may have inadvertently established a noun response set. This finding is at any rate suggestive.

Finally, it should be asked if the possible noun set could have confounded the basic finding of the experiment. We think not. Notice in Table 1 that the proportion of noun responses is quite different under transitive and intransitive stimuli. Thus, if a noun set is operating it might elevate the total number of noun responses, but presumably would not alter the difference in number of noun responses between transitive and intransitive verbs, which is pronounced. Thus, we feel the data support our basic conclusions. Transitive verbs are more difficult to recall. This recall difference seems to be due to implicit association of noun objects to the transitive verbs, and this interpretation has the virtue of being consistent with the currently dominant linguistic view.

\section{REFERENCES}

CHомsкy, N. Aspects of the theory of syntax. Cambridge: M.I.T. Press, 1965.

CHomsky, N. Remarks on nominalization. In R. A. Jacobs \& P. S. Rosenbaum (Eds.), Readings in English transformational grammar. Waltham, Mass.: Blaisdell, in press.

Noble, C. E. An analysis of meaning. Psychological Review, 1952, 59, 421-430.

RoHRMAN, N. L. The role of syntactic structure in the recall of English nominalizations. Journal of Verbal Learning and Verbal Behavior, 1968, 7 , 904-912.

RoHrman, N. L. More on the recall of nominalizations. Journal of Verbal Learning and Verbal Behavior, 1970, 9, 534-536.

Rohrman, N. L., \& Polzella, D. J. Recall of subject nominalizations. Psychonomic Science, 1968, 12, 376-377.

Wall, R. E., Simison, D., \& Stewart, C. A. Recall of causative and transitive verbs. Paper read at the Midwestern Psychological Association meeting, Chicago, May, 1968.

(Received May 4, 1970) 